\title{
Amoxicillin plus omeprazole versus triple therapy for eradication of Helicobacter pylori in duodenal ulcer disease: a prospective, randomized, and controlled study
}

\author{
J Labenz, E Gyenes, G H Rühl, G Börsch
}

\begin{abstract}
Treatment with amoxicillin and omeprazole resulted in encouraging Helicobacter pylori eradication rates in pilot studies that included medium term follow up. These results were evaluated in a prospective, randomised and controlled study. Forty patients with active duodenal ulcer disease and $\boldsymbol{H}$ pylori colonisation of the gastric mucosa were randomly assigned to receive either omeprazole $(20 \mathrm{mg}$ twice daily) and amoxicillin suspension (500 mg four times daily) for two weeks (group I) or bismuth subsalicylate $(600 \mathrm{mg}$ three times daily), metronidazole (400 $\mathrm{mg}$ three times daily), tetracycline ( $500 \mathrm{mg}$ three times daily), and raniditine (300 $\mathrm{mg}$ in the evening) for two weeks (group II). Study medication was followed in both groups by a four week treatment course with $300 \mathrm{mg}$ ranitidine up to the final examination. One patient from each group was lost to follow up. $H$ pylori was eradicated in $78.9 \%$ of group $I$ and $84.2 \%$ of group II $(p=1 \cdot 00)$. All ulcers in patients on omeprazole plus amoxicillin healed but in the triple treatment group four patients had residual peptic lesions after six weeks (ulcer healing rate: $78 \cdot 9 \%, p=0 \cdot 11$ ). Complete pain relief occurred after a median duration of 1 day in group I and of 6 days in group II ( $p=0.03)$. There were no major complications in either group but minor side effects were more frequently recorded in patients on triple therapy $(63.2 \% v 15.8 \%, p<0.01)$. In conclusion, two weeks of treatment with omeprazole plus amoxicillin is as good as triple therapy plus ranitidine in eradicating $\boldsymbol{H}$ pylori but seems better with regard to safety, pain relief, and ulcer healing. Thus, amoxicillin plus omeprazole should be recommended as the treatment of choice in eradicating $\boldsymbol{H}$ pylori in patients with duodenal ulcer disease.

(Gut 1993; 34: 1167-1170)
\end{abstract}

The important role of Helicobacter pylori in idiopathic duodenal ulcer disease has been widely acknowledged since the clear demonstration that ulcer relapse or remission is strongly associated with $H$ pylori colonisation or absence from the gastric mucosa. ${ }^{1-5} H$ pylori therapy is recommended in patients with relapsing duodenal ulcer disease, ${ }^{6}$ but a simple and safe treatment schedule is not yet available. Demanding oral triple therapy eradicates $H$ pylori in up to $96 \%$ of patients treated ${ }^{78}$ but does have considerable side effects. ${ }^{9}{ }^{10}$ Because of this there has been scientific and practical interest in the facts that a monoantibiotic regimen comprising omeprazole and amoxicillin has been highly successful in eradicating $H$ pylori in some pilot studies' " and has shown good results with regard to $H$ pylori reinfection and the clinical course of peptic ulcer disease in the first year after treatment. ${ }^{13}$

These encouraging results in pilot studies required confirmation in prospective and randomised trials. We conducted such a study in patients with active duodenal ulcer disease. The control group was treated with an oral triple therapy regimen which had previously been evaluated in a pilot study. ${ }^{10}$

\section{Methods}

Forty patients who qualified for admission to the study (Tables I and II) were randomly assigned to receive either omeprazole ( $20 \mathrm{mg}$ twice daily) (Antra, Astra Chemicals, Wedel/Holstein, Germany) before meals and amoxicillin suspension (500 mg four times daily) (Amoxypen suspension, Grünenthal, Stolberg, Germany) before meals and at bedtime for two weeks (group I) or bismuth subsalicylate $(600 \mathrm{mg}$ three times daily) (Jatrox, Röhm Pharma, Weiterstadt, Germany) before meals, metronidazole (400 mg three times daily) (Clont 400, Bayer, Leverkusen, Germany) and tetracycline (500 mg three times daily) (Hostacyklin 500, Hoechst, Frankfurt, Germany) after meals, and ranitidine (300 mg at night) for two weeks (group II). After stopping the study medication all patients in both groups continued treatment with $300 \mathrm{mg}$ ranitidine at bedtime for four weeks up to the final follow up examination.

Before starting treatment patients were talked to and were given an information sheet on the basic concepts of the pathophysiology of $H$ pylori infection. They were then asked to participate after a full explanation of the aims and methods of the study, and all gave informed consent. During treatment, patients were asked to consult their study physician if they had side effects. In addition, complaints and side effects were recorded in a diary. Patient compliance was checked with a diary and by counting the number of returned tablets or by calculating the quantity of amoxicillin suspension used, respectively.

Before treatment and after six weeks, patients were investigated clinically, including a symptom score (grade 0: none, grade 1: mild, grade 2: moderate, grade 3: severe complaints due to peptic ulcer disease), and endoscopically. Four
Correspondence to: Dr Joachim Labenz, Elisabeth Hospital, Moltkestr 61, 75138 Essen, Germany.

Accepted for publication 19 January 1993

Department of Medicine
and Laboratory
Medicine, Elisabeth
Hospital, Academic
Teaching Hospital of the
University of Essen,
Germany, and
Department of
Pathology,
Ruhruniversity Bochum,
Germany
J Labenz
E Gyenes
G H Rühl
G Börsch
Correspondence to:
Dr Joachim Labenz,
Department of Medicine,
Elisabeth Hospital, Moltkestr
61, 75138 Essen, Germany.
Accepted for publication
19 January 1993


biopsy specimens of the antrum and four of the gastric body were taken and were analysed by urease test, microscopy of a methylenblue stained mucosal smear, specific culture, and histology after modified Giemsa staining as described elsewhere. ${ }^{1213}$ Both the microbiologist and the pathologist were blinded to the treatment by coding the samples with random numbers. In addition, all patients were assessed for $H$ pylori infection by the ${ }^{13} \mathrm{C}$-urea breath test at the final examination (Prof F E Bauer, University of Göttingen, Germany $\left.{ }^{14}\right)$. Eradication was defined as no evidence of $H$ pylori infection (by urease test, microscopy, culture, histology, urea breath test) four weeks after stopping the study medication

The demographic and clinical characteristics were compared statistically by the Wilcoxon rank sum test (age, ulcer history, pain score) or Fisher's exact test (gender, smoker, alcohol use) and the results of treatment by Fischer's exact test or the log-rank test (pain relief). All statistical analyses were two tailed. Differences were considered significant at a 5\% probability level.

\section{Results}

Forty patients entered the study. The two groups of patients assigned to receive either amoxicillin/omeprazole (group I) or triple therapy plus ranitidine (group II) had similar

TABLE I Patient selection

\begin{tabular}{l}
\hline Inclusion criteria: \\
Active duodenal ulcer disease \\
$H$ pylori status positive \\
Age $18-80$ y \\
Informed consent \\
Exclusion criteria: \\
Additional gastric ulcer \\
Treatment with omeprazole, bismuth compounds, and \\
antibiotics during the 4 weeks before endoscopy \\
History of ulcer surgery including vagotomy $($ except oversewing \\
of ulcer perforation) \\
Pregnancy or lactation \\
Renal insufficiency (creatinine $>2 \cdot 0 \mathrm{mg} / 100 \mathrm{ml} ; 180 \mu \mathrm{mol} / \mathrm{l})$ \\
Congestive heart failure \\
Severe liver disease \\
Disorder of clotting \\
Known penicillin hypersensitivity \\
Lack of compliance
\end{tabular}

TABLE II Demographic and clinical characteristics of

\begin{tabular}{|c|c|c|c|}
\hline & $\begin{array}{l}\text { Amox/ome } \\
(n=20)\end{array}$ & $\begin{array}{l}\text { Triple } \\
\text { therapy } \\
(n=20)\end{array}$ & $p$ \\
\hline Median age (range) $(y)$ & $54 \cdot 5(24-76)$ & $51 \cdot 5(22-75)$ & 0.43 \\
\hline Men/women (n) & & $14 / 6$ & $1 \cdot 00$ \\
\hline $\begin{array}{l}\text { Outpatient/hospitalised (n) } \\
\text { Ulcer history, median }\end{array}$ & $13 / 7$ & $13 / 7$ & \\
\hline (range) $(y)$ & $10 \cdot 5(2-40)$ & $10 \cdot 0(0-40)$ & 0.32 \\
\hline First ulcer (n) & & & \\
\hline $\begin{array}{l}\text { Median number of ulcers in } \\
\text { the last year (range) (n) }\end{array}$ & $2(0-3)$ & $2(0-3)$ & \\
\hline Complicated ulcer disease: & & & \\
\hline $\begin{array}{l}\text { Actual bleeding (n) } \\
\text { History of bleeding (n) }\end{array}$ & $\begin{array}{l}4 \\
5\end{array}$ & $\begin{array}{l}2 \\
5\end{array}$ & \\
\hline History of perforation ( $n$ ) & 0 & 2 & \\
\hline Treatment with H2-blockers & & & \\
\hline$(\mathbf{n})$. & 12 & 11 & \\
\hline Aspirin or NSAID use (n) & 0 & 1 & \\
\hline Smoker (n) & 9 & 8 & 1.00 \\
\hline Alcohol use (n) & 13 & 11 & 0.75 \\
\hline $\begin{array}{l}\text { Median score of epigastric } \\
\text { pain }\end{array}$ & $2 \cdot 5(0-3)$ & $3(0-3)$ & 0.33 \\
\hline Ulcer size (mm) & $5-30$ & $5-12$ & \\
\hline No of ulcers $(1 / 2 / 3)(n)$ & $20 / 0 / 0$ & $16 / 2 / 2$ & \\
\hline
\end{tabular}

Amox/ome: amoxicillin plus omeprazole

$\star$ Plus ranitidine.
TABLE III Overview of the treatment results

\begin{tabular}{|c|c|c|c|}
\hline & $\begin{array}{l}\text { Amox/ome } \\
(n=19)\end{array}$ & $\begin{array}{l}\text { Triple } \\
\text { therapy } \\
(n=19)\end{array}$ & $p$ \\
\hline $\begin{array}{l}\text { H pylori eradication (n (\%)) } \\
\text { Complete ulcer healing }(\mathbf{n}(\%)) \\
\text { Median duration for pain }\end{array}$ & $\begin{array}{l}15 / 19(78 \cdot 9) \\
19 / 19(100)\end{array}$ & $\begin{array}{l}16 / 19(84 \cdot 2) \\
15 / 19(78.9)\end{array}$ & $\begin{array}{l}1 \cdot 00 \\
0 \cdot 11\end{array}$ \\
\hline relief $(\mathrm{d})$ & 1 & 6 & 0.03 \\
\hline $\begin{array}{l}\text { Patients experiencing side } \\
\text { effects }(\mathbf{n}(\%))\end{array}$ & $3(15 \cdot 8)$ & $12(63 \cdot 2)$ & 0.01 \\
\hline
\end{tabular}

Amox/ome $=$ amoxicillin plus omeprazole

$\star$ Plus ranitidine.

demographic and clinical characteristics (Table II). One patient in each group was lost to follow up. Compliance was good ( $>95 \%$ consumption of the delivered study medication) in all group I patients and in 18 of 19 patients in group II. One group II patient refused his morning medication (bismuth subsalicylate, metronidazole, tetracycline) in the second week because of disturbing fatigue.

Before treatment, $H$ pylori colonisation of the gastric mucosa had been detected by urease test and histology in all patients (microscopically after methylenblue staining in 37 , and culture in 31 patients).

Epigastric pain was the main clinical symptom of duodenal ulcer disease: this was experienced by all patients before entering the study. Complete pain relief occurred after a median time of 1 day ( $25 \%$ quantile: $0 \cdot 0-75 \%$ quantile: $3.0)$ in the amoxicillin/omeprazole group and of 6 days ( $25 \%$ quantile: $5 \cdot 0-75 \%$ quantile: $10 \cdot 0)$ in the triple therapy group $(p=0 \cdot 03)$. After six weeks, complete ulcer healing was observed endoscopically in all group I patients and in 15 of 19 patients $(78.9 \%)$ in group II $(\mathrm{p}=0 \cdot 11)$. We detected residual peptic lesions in the duodenal bulb of four group II patients at the final follow up examination. These were associated with successful $H$ pylori eradication in three cases and with treatment failure in one patient. The overall proportion of $H$ pylori eradication was $78.9 \%$ after combined amoxicillin/omeprazole treatment and $84 \cdot 2 \%$ after triple therapy plus ranitidine $(p=1 \cdot 00)$.

Before treatment, histology showed that all patients had chronic active gastritis, predominantely in the antral region. Successful $H$ pylori eradication resulted in improvement of moderate or severe gastritis in 26 of $\mathbf{3 1}$ patients, complete healing of moderate gastritis in one patient, unchanged histology in four patients with mild to moderate lymphocytic infiltration, and total disappearance of polymorphonuclear leukocytes in all but one patient (Figure A, B, D, and E). Treatment failure was accompanied by a slight improvement of gastritis in one patient, by similar histology before and after treatment in four cases, and by worsening gastric mucosal inflammation in two patients (Figure C). In these patients, gastritis activity was improved in three, unchanged in three, and worse in one (Figure F).

There were no major side effects that interrupted treatment in either group. Three patients from the amoxicillin/omeprazole group complained of side effects $(15 \cdot 8 \%$; mouth burning: $\mathrm{n}=2$, pruritus: $\mathrm{n}=1$ ), whereas undesired effects were reported in 12 of 19 patients in the triple 
therapy group $(63 \cdot 2 \%$; diarrhoea: $n=4$, sleep disturbances: $n=2$, dizziness: $n=2$, paresthesias of the legs: $n=2$, anal pruritus: $n=2$, mouth burning: $n=1$, nausea: $n=1$, fatigue: $n=1$ ). All side effects disappeared spontaneously after stopping the study medication. The proportions of minor side effects experienced were significantly different in the two treatment groups $(\mathrm{p}<0.01)$.

\section{Discussion}

Several studies have shown that the eradication of $H$ pylori is associated with a considerable reduction in the rate of recurrence of duodenal and gastric ulcers, but how and why this occurs is still a matter of debate. ${ }^{15}$ Because bismuth and antibiotic monotherapy fail to eradicate $H$ pylori in an appreciable proportion of patients, ${ }^{16}$ triple therapy (for example bismuth, metronidazole, and tetracycline or amoxicillin) has been tried and is now the treatment of choice. ${ }^{6}{ }^{16}$ Patients treated with triple therapy, however, complain of considerable side effects which endangers compliance in routine clinical practice. In several pilot studies, we obtained $H$ pylori eradication with a low complication rate in approximately $60-80 \%$ of patients treated with an omeprazole modified monoantibiotic therapy with amoxicillin." Bacterial eradication resulted in a dramatic change in the natural history of duodenal and gastric ulcer disease in the first year
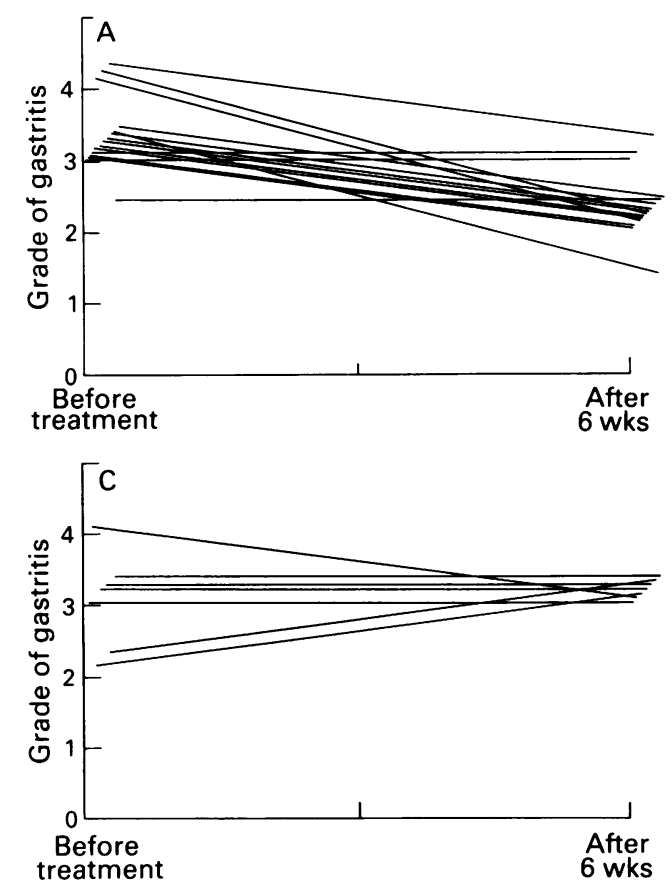

Changes of grade and activity of antral gastritis (1: minimal, 2 : mild, 3 : moderate, 4: severe) associated with

Helicobacter pylori eradication induced by amoxicillin/omeprazole treatment $(A, D)$ or oral triple therapy plus ranitidine $(B, E)$. Grade and activity of antral gastritis associated with treatment failure (both groups, $C$ and $F$ ).

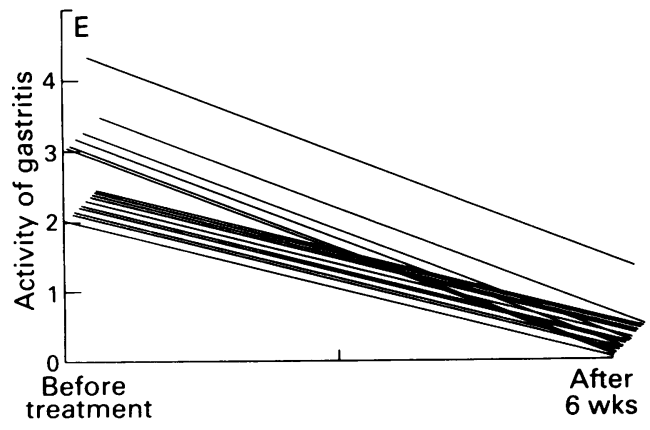

after treatment. ${ }^{3}$ These encouraging results were confirmed by Bayerdörffer et al,' but other authors reported a lack of efficacy of the combined amoxicillin/omeprazole treatment, probably because of different dosage regimens, the kind of amoxicillin preparation used, or omeprazole pretreatment. ${ }^{11}$

There is still no satisfactory explanation for the much greater efficacy of a combined omeprazole/amoxicillin treatment regimen. Omeprazole alone acts bacteriostatically on $H$ pylori in vitro, with MIC values in the range of bismuth salts, ${ }^{17}$ but there are no data on its in vivo mechanism of action. Omeprazole monotherapy merely suppressed bacterial colonisation, especially in the antral region, and eradicated $H$ pylori in individual cases only..$^{18}$ It seems more likely that the decisive factor is the improvement in the antibacterial activity of amoxicillin after profound inhibition of acid secretion, because the MIC values of amoxicillin against $H$ pylori are appreciably lower at neutral $\mathrm{pH}$, for example, than at a $\mathrm{pH}$ of $5 \cdot 5 .{ }^{19} \mathrm{In}$ addition, therapeutically induced anacidity may result in bacterial overgrowth of the stomach, with consecutive displacement of $H$ pylori. ${ }^{2021}$ The latter hypothesis is supported by the observation that $H$ pylori colonisation is rarely found in patients with anacidity caused by type A gastritis. ${ }^{22}$

The promising possibility of omeprazole enhanced antibiotic treatment for $H$ pylori associated diseases cannot be assumed uncondi-
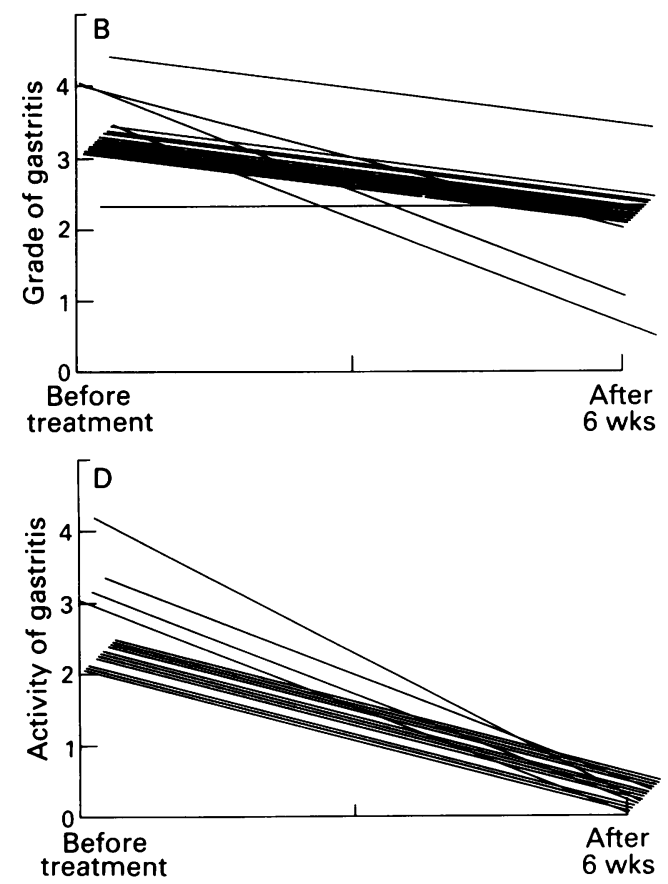
tionally for antimicrobial compounds other than amoxicillin. In small scale pilot studies omeprazole plus ciprofloxacin or cefixime failed to eradicate $H$ pylori in the vast majority of patients." In a recently published pilot study, however, an $H$ pylori eradication rate of $80 \%$ was achieved after two weeks' treatment with omeprazole $(40 \mathrm{mg})$ and the new macrolide antibiotic clarithromycin (500 $\mathrm{mg}$ three times daily). ${ }^{23}$

In this study, the new treatment strategy of 'anacidity enhanced antibiotic treatment' was compared for the first time with a previously evaluated triple therapy regimen $(H$ pylori eradication rate: $92 \%) .{ }^{10}$ The results suggest that these treatment regimens are equally effective in producing $H$ pylori eradication, but amoxicillin/ omeprazole is better with regard to side effects, pain relief, and probably ulcer healing. There was indeed a trend towards higher eradication rates in the triple therapy group $(84.2 v 78.9 \%)$, but this lacked statistical significance because of the rather small sample size. A study with the power to show clearly that a $5 \%$ yield difference was truly present or absent would have required a prohibitively high number of 2336 study subjects (power $80 \%$ ). Giving the drugs four times daily in the triple therapy group might have further improved the treatment results. In our experience, however, the three times daily dosing gives eradication rates of approximately $90 \%$, well in accordance with published figures on four times daily dosing. The potential advantage of more frequent dosing would have been at most a rather small one therefore and would not have changed the main conclusions of this study. In Germany, the two treatment schedules evaluated in this study are equally expensive. It therefore seems justified to recommend amoxicillin/omeprazole as the treatment of choice to eradicate $H$ pylori in $H$ pylori related gastroduodenal diseases. Triple therapy might be reserved for patients with treatment failure or with suspected penicillin hypersensitivity. Further studies are required to establish the optimal dosages of omeprazole and amoxicillin (or other antibiotics), the frequency and the galenic formula (amoxicillin suspension or tablet?) of the constituents, as well as the relation to meals (pre- or postprandially) and the required minimal duration of treatment.

1 Bayerdörffer E, Mannes GA, Sommer A, Höchter W, Weingart J, Hatz R, Lehn N, Ruckdeschel G, Dirschedl P, Stolte $M$. High dose emeprazole treatment combined with amoxicillin eradicates Helicobacter pylori. European fourna of Gastroenterology and Hepatology 1992; 4: 697-702.

2 Graham DY, Lew GM, Klein PD, Evans DG, Evans DJ, Saeed ZA, Malaty HM. Effect of treatment of Helicobacter pylori infection on the long-term recurrence of gastric or duodenal ulcer. Ann Intern Med 1992; 116:705-8

3 Labenz J, Gyenes E, Rühl GH, Börsch G. Helicobacter pylori reinfection and clinical course of peptic ulcer disease in the first year post amoxicillin/omeprazole treatment. European foumal post amoxicillin/omeprazole treatment. European fournal of Gastroenterology and Hepatology 1992; 4: 893-6. Marshall BJ, Goodwin CS, Warren JR, Murray R, Blincow D Blackbourn SJ, Phillips M, Waters TE, Sanderson CR Prospective double-blind trial of duodenal ulcer relapse afte eradication of Campylobacter pylori. Lancet 1988; ii: $1437-$ 42.

5 Rauws EAJ, Tytgat GNJ. Cure of duodenal ulcer associated with eradication of Helicobacter pylori. Lancet 1990; ii: 1233-5.

6 Tytgat GNJ, Axon ATR, Dixon MF, Graham DY, Lee A Marshall BJ. Helicobacter pylori: causal agent in peptic ulcer disease? Oxford: Blackwell Scientific Publications, 1990: 3645. Working party report. World Congresses of Gastroenterology: 26th-31st August 1990, Sydney, Australia.

7 Börsch G, Wegener M, Mai U, Opferkuch W. Efficiency of oral triple therapy to eradicate Campylobacter pylori. In: Megraud F, Lamouliatte $\mathrm{H}$, eds. Gastroduodenal patholog and Campylobacter pylori. Ads. Gastroduodenal pathology and $C$.

8 Borody TJ, Brandl S, Andrews P, Ostapowicz N, Jankiewicz E. High efficacy, low dose triple therapy for Helicobacter pylori. Gastroenterology 1992; 102: A44.

9 Borody TJ, Cole P, Noonan S, Morgan A, Ossip G, Maysay J, Brandl S. Long-term Campylobacter recurrence posteradication. Gastroenterology 1988; 94: A43.

10 Labenz J, Gyenes E, Rühl GH, Börsch G. Efficiency of oral triple therapy (BSS/metronidazole/tetracycline) to eradicate $H P$ in DU disease. Ir $\mathcal{Y} M e d S c i$ 1992; 161: 90.

11 Labenz J, Gyenes E, Rühl GH, Börsch G. Efficacy of omeprazole and amoxicillin to eradicate HP. Am $\mathscr{J}$ Gastroenterol 1992; 87: 1271 .

12 Börsch G, Labenz J, Rehner M, Rühl GH, Gyenes E. Nachweis von Helicobacter pylori. Münchner Meditinische Nachweis von Helicobacter pylor
Wochenschrift 1990; 132: 391-4.

13 Labenz J, Gyenes E, Rühl GH, Peitz U, Börsch G. Diagnosi of Helicobacter pylori colonization of gastric mucosa. A prospective comparative study of direct tests and validity of a new urease test. Med Klin 1991; 86: 461-4.

14 Lotterer E, Ramaker J, Lüdtke FE, Tegeler R, Geletneky JV Bauer FE. The simplified ${ }^{13} \mathrm{C}$-urea breath test - one poin analysis for detection of Helicobacter pylori. Z Gastroenterol (Vrh) 1991; 29: 590-4

15 Graham DY, Börsch GMA. The who's and when's of therapy for Helicobacter pylori. Am $\mathcal{F}$ Gastroenterol 1990; 85: 1552-5.

16 Börsch GMA, Graham DY. Helicobacter pylori. In: Benjamin SB, Collen MJ, eds. Pharmacology of peptic ulcer disease. Berlin: Springer, 1991: 107-47. (Handbook of experimental Berlin: Springer, 1991:

17 De Koster E, Nyst JF, Glupczynski Y, Jonas C, Denis P, van Geel J, De Reuck M, Deltenre M. Omeprazole and $H p$ : the long and winding road. Italian fournal of Gastroenterology $1991 ; 23($ suppl 2): 2 .

18 Stolte M, Bethge B. Elimination of Helicobacter pylori unde treatment with omeprazole. Z Gastroenterol $(V r h) 1990 ; 28$ : $271-4$.

19 McNulty CAM. Bacteriological and pharmacological basis for the treatment of Campylobacter pylori infection. In: Rathbone BJ, Heatley RV, eds. Campylobacter pylori and gastroduodenal disease. Oxford: Blackwell Scientific gastroduodenal disease.

20 Armstrong D, Viani F, Siegrist H, Pignatelli B, Idström JP Cederberg C, Blum AL, Fried M. Does omeprazole increase gastric bacterial counts, nitrite or total nitrose compounds gastric bacterial counts, nitrite or total nitrose compounds
(NOC) in healthy subjects? Gastroenterology 1992; 102: A34

(NOC) in healthy subjects? Gastroenterology 1992; 102: A34.
21 Bhatia SJ, Kochar N, Abraham P, Nair NG, Mehta AP Lactobacillus acidophilus inhibits growth of Campylobacter pylori in vitro. $\mathcal{F}$ Clin Microbiol 1989; 27: 2328-30

22 Fong TL, Dooley CP, Dehesa M, Cohen H, Carmel R, Fitzgibbons PL, Perez-Perez GI, Blaser MJ. Helicobacter pylori infection in pernicious anemia: a prospective controlled study. Gastroenterology 1991; 100: 328-32.

23 Logan RPH, Gummett PA, Hegarty BT, Walker MM, Baron $\mathrm{JH}$, Misiewicz JJ. Clarithromycin and omeprazole for Helicobacter pylori. Lancet 1992; 340: 239. 